\title{
Signal-to-Noise Analysis of the Differential Open Photoacoustic Helmholtz Cell
}

\author{
Antonina Geras
}

Received: 28 April 2014 / Accepted: 28 August 2014 / Published online: 29 October 2014 (C) The Author(s) 2014. This article is published with open access at Springerlink.com

\begin{abstract}
When open photoacoustic cells are considered, attenuation of external noise is a serious issue. This paper describes how mechanical dimensions of a differential open photoacoustic Helmholtz cell influence its signal-to-noise (S/N) ratio. The analysis was performed by means of computer simulations based on the loss-improved transmission line model. This research showed that the mechanical parameters noticeably affect the signal-to-noise ratio. According to the presented results, optimal selection of the dimensions is a factor which can substantially improve the signal-to-noise ratio of the examined photoacoustic cell. Due to the very good acoustic properties of the cell, it should be possible to obtain an S/N ratio of over $100 \mathrm{~dB}$.
\end{abstract}

Keywords Differential detection - Differential open photoacoustic cell · Helmholtz resonator - Parametric analysis · Photoacoustic cell improvement . Signal-to-noise ratio

\section{Introduction}

The photoacoustic effect was discovered by Bell in the nineteenth century [1], but because of a lack of coherent light sources and methods for sound analysis, its full potential could not be employed at those times. It changed when lasers became commercially available and were introduced as excitation sources in photoacoustic setups [2-5]. Furthermore, high-sensitive microphones, as well as semiconductor devices necessary for signal analysis, were developed and could be easily used as components of photoacoustic measurement instrumentation. Currently, the photoacoustic method is often used for detection of trace gases such as explosives, toxic gases, and

\footnotetext{
A. Geras $(\varangle)$

Institute of Electronic Systems, Warsaw University of Technology,

Nowowiejska 15/19, 00-665 Warsaw, Poland

e-mail: antonina@geras.pl
} 
pollutants [6-10]. It can also be applied to in vivo measurements since, in contrast to other spectroscopic methods, it is non-invasive and non-destructive [11-14]. In many of these applications, a continuous flow of the gas being measured is required. This is why open, rather than closed, photoacoustic cells are convenient as components of instrumentation designed for such measurements. The major drawback of no isolation between the cell and the environment when the measurement is performed is that the external acoustic noise can enter the cell and disturb the photoacoustic signal [15]. A well-known solution to this problem is to use acoustic buffers for external noise attenuation [16]. Another method, which seems particularly promising, is differential detection, since it allows for doubling the signal amplitude with simultaneous strong noise reduction [17-19]. A differential open Helmholtz cell was proposed by Starecki and Geras [20]. This paper describes how mechanical parameters of such a cell influence its signal-to-noise ratio. This measure is a common criteria for evaluation of the sensitivity of measurement instruments [10,21]. Some remarks on how the dimensions of differential cells influence the frequency response can be found in the literature $[17,19]$. However, none of these reports contains a full analysis of all of the parameters' influences and their interactions. The presented research should allow for choosing optimal mechanical parameters of the cell before its manufacturing, thus possibly helping to obtain the best experimental results.

\section{Differential Open Photoacoustic Helmholtz Cell}

The simplest differential photoacoustic cell consists of two identical cavities. In one of the cavities, the photoacoustic signal is triggered and measured, while in the second cavity, only the noise is measured. The final signal is the difference between these two outputs. Such setups are quite popular in the literature [6,7,22-24]. The differential photoacoustic cell of this structure can be used for microphones calibration, as sometimes it is necessary to calibrate a microphone as a function of wavelength, frequency, or temperature. If the calibration measurement is done before the sample measurement, the experimental conditions are changed, and such a calibration is not reliable [23]. With the differential cell, it would be possible to obtain signals from the reference sample and the sample being tested simultaneously, which would allow for proper setting of the microphone [25].

Another possible differential detection scheme is to excite and measure the signal in both cavities $[8,17,18,25,26]$. If the sample components in the cavities are in counterphase, then subtraction should double the amplitude of the photoacoustic signal and cancel the noise components $[8,9,17,19,26]$. Such a situation occurs in the Helmholtz resonator, so it was incorporated in the design of the differential open photoacoustic cell of a structure as in Fig. 1 [20].

A detailed description of the principles of the Helmholtz resonator operation can be found elsewhere $[10,19,27]$. Here, it is important to highlight that due to the pistonlike gas movement between the cavities, the excited signals are in counterphase $[8,17]$. It should be noted that although in the case of a Helmholtz resonator the Q-factor is low in comparison to that of other types of resonators (usually not greater than 20 $[10,28])$, the low volume of the cavities allows for the attainment of a high level of 

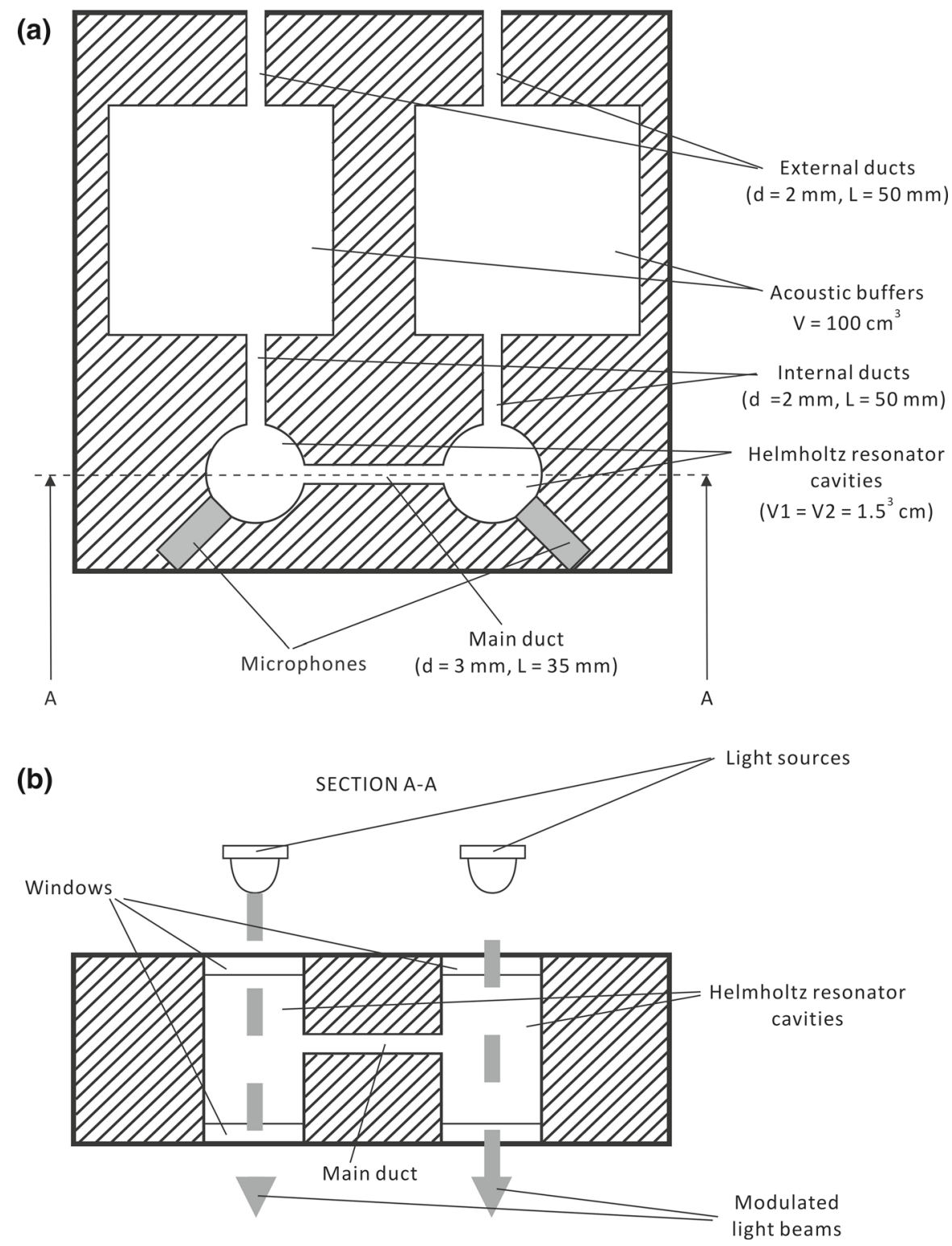

Fig. 1 Differential open photoacoustic Helmholtz cell with dimensions as in the reference cell (a) horizontal cross section and (b) vertical cross section [14]

photoacoustic signal amplitude $[8,10]$, as it is inversely proportional to the volume of the cell, according to the formula,

$$
A \propto \frac{\alpha P}{f V},
$$


where $\alpha$ is the light absorption coefficient, $P$ is the light power, $f$ is the light intensity modulation frequency, and $V$ is the volume of the cell $[4,15,23]$. In the proposed cell, the cavities have a volume of $1.5 \mathrm{~cm}^{3}$ and the connecting duct has a length of $35 \mathrm{~mm}$ and a diameter of $3 \mathrm{~mm}$. For such dimensions, the resonance frequency of the cell should be about $900 \mathrm{~Hz}$, according to the equation,

$$
f_{\mathrm{res}}=\frac{v d}{4 \pi} \sqrt{\frac{\pi}{l} \frac{V_{1}+V_{2}}{V_{1} V_{2}}}
$$

where $V_{1}$ and $V_{2}$ are the volumes of the cavities, $l$ is the length of the duct, $d$ is the diameter of the duct, and $v$ is the sound speed in the gas filling the cell.

Both of the resonator cavities are equipped with windows and symmetrically located microphones. Because the cell was designed as an open one, it was necessary to provide means for prevention of the external noise infiltration. For this reason, cavities of relatively big volumes were symmetrically attached to the resonator cavities. They are expected to operate as acoustic buffers and attenuate the external noise. The inlet/outlet ducts (denoted as the "external ducts" in Fig. 1, as well as the ducts connecting the Helmholtz resonator with the buffers (denoted as the "internal ducts") also can help in noise attenuation. Those ducts can be considered as transmission lines. If their length is equal to a quarter of the length of the acoustic wave corresponding to the light frequency modulation, the ducts transform low acoustic impedance connected at one end into high acoustic impedance at the other end of the duct. As a result, a duct-buffer-duct structure can be considered as a bidirectional stop-band filter, which should further reduce external noise infiltration [15]. It is crucial that the inlets of the cavities should be positioned close to each other and symmetrically. Otherwise, the external noise would not penetrate them equally, so subtraction of the noise measured under different conditions could lead to unreliable results. As previously examined $[20,29]$, the frequency response of the proposed differential cell is, in the resonance frequency region, virtually the same as in the case of the open Helmholtz cell of the same dimensions. The frequency peak is neither damped nor shifted. Furthermore, it remains almost unchanged with regard to the closed Helmholtz cell [20]. These observations confirm that the Helmholtz resonator can be modified in various ways in order to obtain better noise attenuation without diminishing the Q-factor or noticeably changing the resonance frequency.

\section{Modeling Method}

To analyze the properties of the differential open photoacoustic Helmholtz cell, a method of acousto-electric analogies can be used [8-10,30]. Its principle is to transform each of the acoustic components of the cell into its electric counterpart [31-33]. Although this method is quite popular, its results do not always correspond precisely to those obtained from measurements $[27,30]$. It was found that the transmission line model gives much better information on the cell behavior [27,30]. Thus, the improved transmission line model, as introduced by Starecki [27,30] was employed in this research. The model of the differential cell described in this paper has been previously 
presented in detail [29], so will not be repeated here. Based on this model, a series of simulations using computer software was performed to calculate the frequency response of the cell, the external noise infiltration, and finally, the signal-to-noise ratio.

\section{Modeling Results}

This research aimed to discover how the dimensions of the differential open Helmholtz cell affect its performance and to find the dimensions that result in the best signal-tonoise ratio. In order to achieve this goal, as a first step, a reference cell was examined, and then the dimensions (duct lengths and diameters, buffer volumes) were changed (only one per simulation). The dimensions of the reference cell were the following: cavities, $1.5 \mathrm{~cm}^{3}$ each; buffer volume, $100 \mathrm{~cm}^{3}$; main duct length, $35 \mathrm{~mm}$; diameter, $3 \mathrm{~mm}$; internal and external ducts, $50 \mathrm{~mm}$ in length and $2 \mathrm{~mm}$ in diameter (Fig. 1).

The length of the internal and external ducts was changed from $25 \mathrm{~mm}$ to $125 \mathrm{~mm}$ in steps of $25 \mathrm{~mm}$. It was discovered that, as in the previous analyses of Helmholtz cells $[29,34,35]$, the best result is obtained for an intermediate value. According to the simulations, in the case of the internal ducts, the signal-to-noise ratio is best at a length of $100 \mathrm{~mm}$, while in the case of the external duct, the signal-to-noise ratio is best at a length of $125 \mathrm{~mm}$ (Fig. 2). This value corresponds to a quarter of the wavelength of the induced acoustic wave, so the previous assumption that such a length should help to attenuate the external noise is confirmed. When considering the duct diameters (Fig. 3), it is clear that the smaller the diameter, the better is the signal-to-noise ratio. This fact is not surprising, as it was already known that less acoustic noise can enter
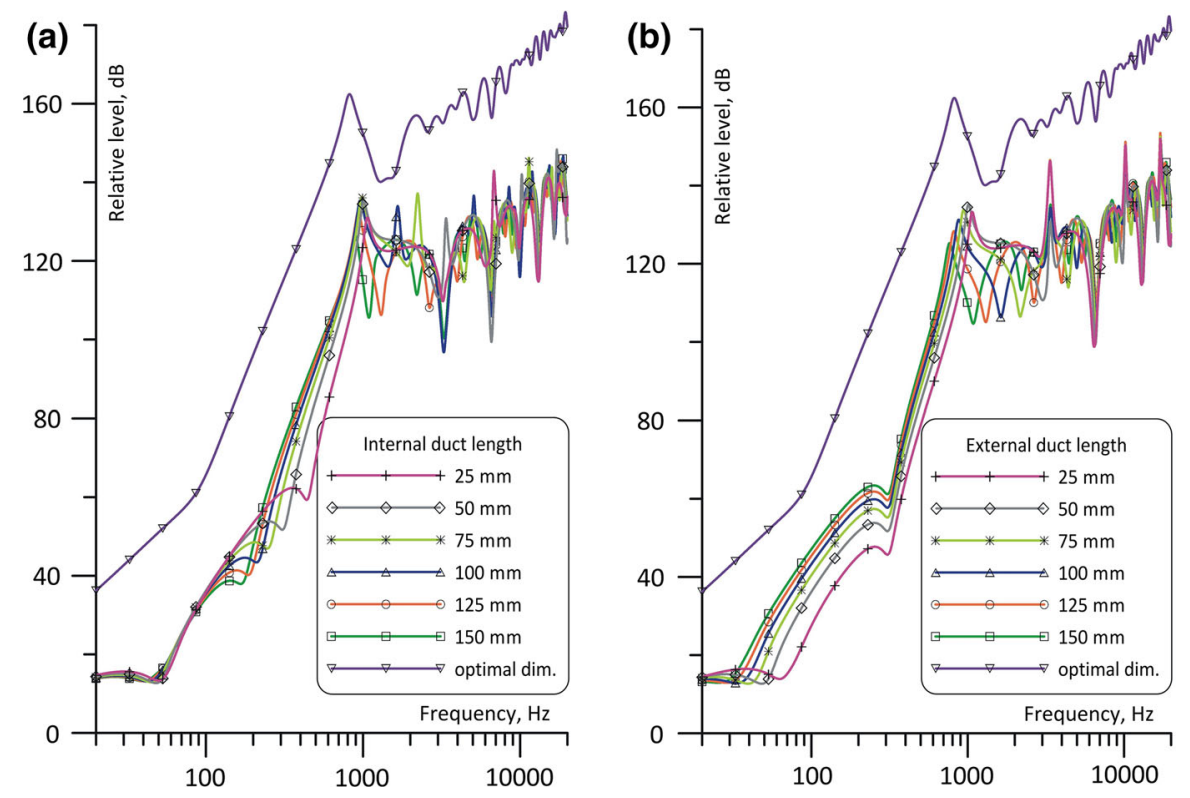

Fig. 2 Signal-to-noise ratio of the open photoacoustic differential Helmholtz cell with different (a) internal and (b) external duct lengths 

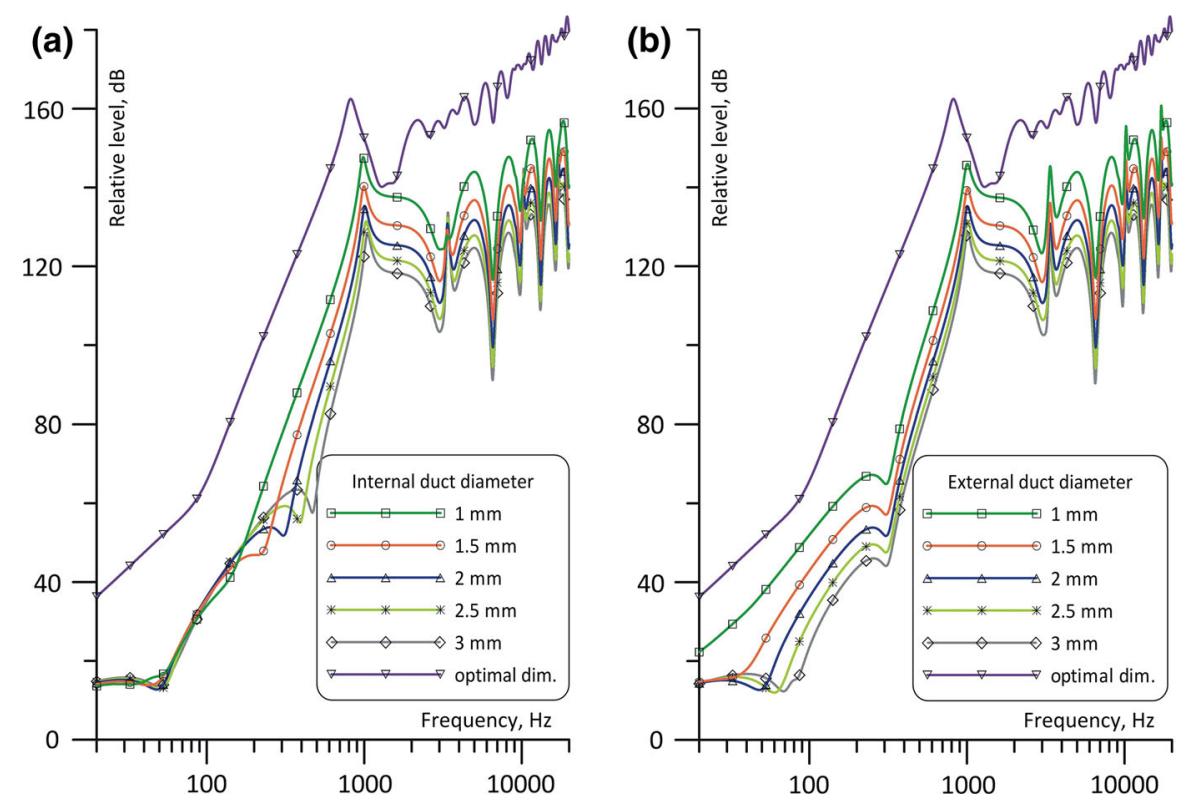

Fig. 3 Signal-to-noise ratio of the open photoacoustic differential Helmholtz cell with different (a) internal and (b) external duct diameters

through a narrow duct than through a wide one. There are two limitations in choosing the smallest duct. The first is that the diameter of the inlet determines the flow rate of the gas exchange between the cell and ambient, so if the system response time is crucial, ducts of greater diameter should be considered [16]. The second inconvenience is that ducts of such a small diameter are very difficult to fabricate, especially if their length would be greater than just a few centimeters. It may be useful to note that a change in dimension, from $1 \mathrm{~mm}$ to $2 \mathrm{~mm}$, results in only about $10 \mathrm{~dB}$ deterioration of the signal-to-noise ratio. The volume of the buffers has a significant influence on the cell performance (Fig. 4). A change from $10 \mathrm{~cm}^{3}$ to $250 \mathrm{~cm}^{3}$ results in almost a $40 \mathrm{~dB}$ improvement of the signal-to-noise ratio. Similarly, as in the case of the duct diameters, the volume of the buffers affects the speed of the gas exchange. Thus, from a practical point of view, incorporating buffers of very high volume is not always acceptable $[10,16]$.

When all the dimensions were examined, a cell with the values that led to the best signal-to-noise ratio was inspected. This result is denoted as "optimal dimensions" in Figs. 1, 2, 3, and 4. When looking at these graphs, it is clear that such a combination results in a much better signal-to-noise ratio than in the case where only one of the dimensions is optimal.

\section{Conclusions}

From the presented analysis, it can be concluded that the influence of the dimensions of the cell components on the signal-to-noise ratio is strong. In the case of the buffer 
Fig. 4 Signal-to-noise ratio of the open photoacoustic differential Helmholtz cell with different volumes of the buffers

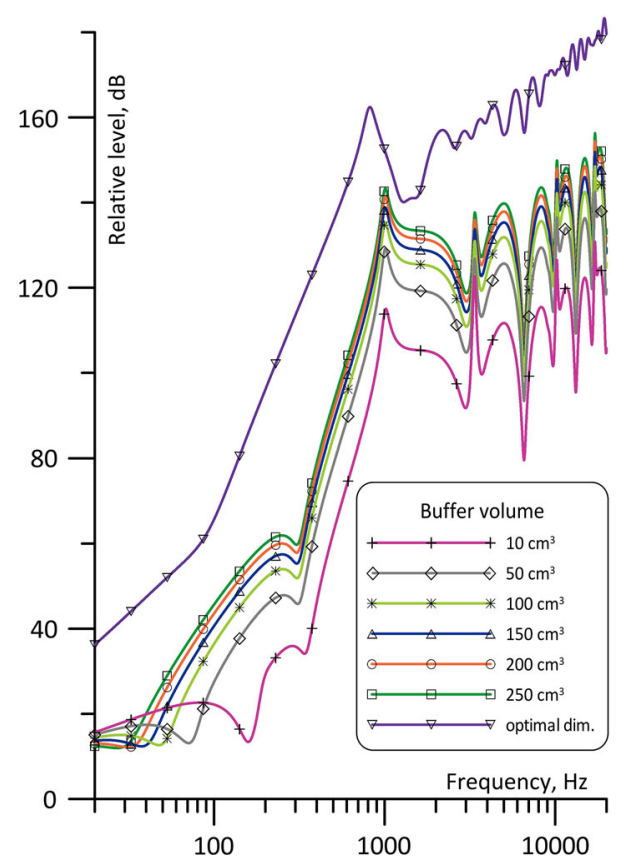

volume, it is obvious that it should be as big as possible, and in the case of the diameters, it is clear that the recommended diameter is the smallest one. Those parameters are restricted only by practical limitations such as the expected flow rate, the size of the cell, and manufacturing capabilities. Selection of the duct lengths is not as straightforward as one might think. According to the simulations, the optimal results are obtained for a value close to a quarter of the wavelength of the resonance frequency. It is worth noting that when all of the dimensions are set to those for which the results were the best separately, the final signal-to-noise ratio is significantly greater-over $100 \mathrm{~dB}$. Furthermore, this analysis takes into consideration the acoustical properties of the cell only (i.e., examines how the external acoustic noise penetrates the cavities). In reality, when the signal is measured with two microphones, this noise will be additionally reduced by means of the differential detection.

Open Access This article is distributed under the terms of the Creative Commons Attribution License which permits any use, distribution, and reproduction in any medium, provided the original author(s) and the source are credited.

\section{References}

1. A.G. Bell, Am. J. Sci. 20, 305 (1880)

2. C.F. Dewey, R.D. Kamm, C.E. Hackett, Appl. Phys. Lett. 23, 11 (1973)

3. D.J. Brassington, J. Phys. D 15, 219 (1982)

4. Z. Bozóki, J. Sneider, G. Szabó, A. Miklós, M. Serényi, G. Nagy, M. Fehér, Appl. Phys. B 63, 399 (1996) 
5. Z. Bozóki, A. Szabó, Á. Mohácsi, G. Szabó, Z. Bor, M. Erdélyi, W. Chen, F. Tittel, Appl. Spectrosc. 56, 715 (2002)

6. R.E. Lindley, A.M. Parkes, K.A. Keen, E.D. McNaghten, A.J. Orr-Ewing, Appl. Phys. B 86, 707 (2007)

7. J. Uotila, V. Koskinen, J. Kauppinen, Vib. Spectrosc. 38, 3 (2005)

8. V. Zeninari, V.A. Kapitanov, D. Curtois, Y. Ponomarev, Infrared Phys. Technol. 40, 1 (1999)

9. V.A. Kapitanov, Yu.N. Ponomarev, K. Song, H.K. Cha, J. Lee, Appl. Phys. B 73, 745 (2001)

10. A. Miklós, P. Hess, Z. Bozóki, Rev. Sci. Instrum. 72, 1937 (2001)

11. J. Yao, K.I. Maslov, L.V. Wang, Proc. SPIE 8223, 82230U-1 (2012)

12. J. Kottmann, J.M. Rey, M.W. Sigrist, Proc. SPIE 8223, 82231A-1 (2012)

13. T. Berer, A. Hochreiner, H. Grün, P. Burgholzer, Proc. SPIE 8223, 82231G-1 (2012)

14. G. Rousseau, D. Lévesque, A. Blouin, J.-P. Monchalin, Proc. SPIE 8223, 82231C-1 (2012)

15. T. Starecki, Acta Phys. Pol. A 114, 199 (2008)

16. Z. Bozóki, A. Szabó, Á. Mohácsi, G. Szabó, Sens. Actuators B 147, 206 (2010)

17. G. Busse, D. Herboeck, Appl. Opt. 18, 3959 (1979)

18. S.V. Egerev, A.V. Fokin, A.E. Pashin, Rev. Sci. Instrum. 67, 2691 (1996)

19. K. Song, H.K. Cha, V.A. Kapitanov, Yu.N. Ponomarev, A.P. Rostov, D. Curtois, B. Parvitte, V. Zeninari, Appl. Phys. B 75, 215 (2002)

20. T. Starecki, A. Geras, Int. J. Thermophys. (2014). doi:10.1007/s10765-014-1570-z

21. D. Ducharme, A. Tessier, R.M. Leblanc, Rev. Sci. Instrum. 50, 1461 (1979)

22. D. Cahen, E. Itzhak Lerner, A. Auerbach, Rev. Sci. Instrum. 49, 1206 (1978)

23. M.E. Rodríguez-García, R. Velásquez-Hernández, M.L. Mendoza-López, D.M. Hurtado-Castañeda, K.M. Brieño-Enríquez, J.J. Pérez-Bueno, Rev. Sci. Instrum. 78, 034904 (2007)

24. J. Uotila, Eur. Phys. J. Spec. Top. 153, 401 (2008)

25. A. Gutiérrez, J. Giraldo, R. Velázquez-Hernández, M.L. Mendoza-López, D.G. Espinosa-Arbeláez, A. del Real, M.E. Rodríguez-García, Rev. Sci. Instrum. 81, 013901 (2010)

26. H.S. Lee, D.D. Lee, Appl. Opt. 27, 10 (1988)

27. T. Starecki, K. Opalska, A. Burd, S. Misiaszek, M. Ramotowski, Proc. SPIE 5948, 5948M-1 (2005)

28. T. Starecki, A. Burd, S. Misiaszek, K. Opalska, M. Radtke, M. Ramotowski, in Proceedings of Krajowa Konferencja Elektroniki (Koszalin, Poland, 2003), p. 653 [in Polish]

29. A. Geras, T. Starecki, Int. J. Thermophys. (2014). doi:10.1007/s10765-014-1583-7

30. T. Starecki, Proc. SPIE 6159, 6159M-1 (2006)

31. O. Nordhaus, J. Pelzl, Appl. Phys. 25, 221 (1981)

32. J. Pelzl, K. Klein, O. Nordhaus, Appl. Opt. 21, 94 (1982)

33. R. Kästle, M.W. Sigrist, Appl. Phys. B 63, 389 (1996)

34. A. Geras, T. Starecki, Int. J. Thermophys. (2013). doi:10.1007/s10765-013-1497-9

35. A. Geras, Int. J. Thermophys. (2014). doi:10.1007/s10765-014-1735-9 